\title{
Relationships between Cognitive Flexibility, Perceived Quality of Faculty Life, Learning Approaches, and Academic Achievement
}

\author{
Çetin Toraman \\ Asst. Prof., Çanakkale Onsekiz Mart University, toramanacademic@gmail.com \\ Hasan Fehmi Özdemir \\ Ankara University, hasan.f.ozdemir@ankara.edu.tr
}

\author{
Ayşen Melek Aytuğ Koşan \\ Çanakkale Onsekiz Mart University, aysenayl@yahoo.com
}

\section{Senol Orakcı}

Aksaray University, senolorak@gmail.com

\begin{abstract}
This study aims to explore the relationships between cognitive flexibility (CF), perceived quality of faculty life (PQFL), learning approaches (LA) and academic achievement (AA). This correlational comparison study was conducted with 1573 undergraduates at Ankara University. The data collection tools were "Cognitive Flexibility Scale (CFS)", "Quality of Faculty Life Scale (QFLS)" and "Approaches to Learning Questionnaire (ALQ)". Grade point average (GPA) was used as a measurement of AA. The three subscales of QFLS; satisfaction from faculty (SF), faculty members (SFM), and school climate and student relationships (SSCSR) were found positively correlated with deep approach to learning (DAL), CF and AA, and negatively correlated with surface approach to learning (SAL). DAL was also found positively correlated with $\mathrm{CF}$ and AA, but negatively correlated with SAL. CF and AA were positively correlated with all variables, except SAL. Although CF showed a positive correlation with AA, it assumed a negative explanatory role for AA when it was included in the model as a mediating variable. The regression estimates in the path analysis model revealed that DAL, SAL and SF were positive explanatory variables for AA, whereas SSCSR was a negative explanatory variable for AA and SAL was a negative explanatory variable for $\mathrm{CF}$.
\end{abstract}

Keywords: cognitive flexibility, quality of faculty life, learning approaches, academic achievement, path analysis

Citation: Toraman, Ç., Özdemir, H. F., Aytuğ Koşan, A. M., \& Orakcı, Ş. (2020). Relationships between Cognitive Flexibility, Perceived Quality of Faculty Life, Learning Approaches, and Academic Achievement. International Journal of Instruction, 13(1), 85-100. https://doi.org/10.29333/iji.2020.1316a 


\section{INTRODUCTION}

$\mathrm{CF}$ refers to an individual's awareness of the availability of options and attainable alternatives in all situations and their ability to adapt to various circumstances (Martin \& Anderson, 1998). Individuals who have this ability, compelling and inconsistent thoughts are replaced by balanced and adaptable thoughts; they can create alternatives and elaborate challenges to be able to cope with them (Gulum \& Dag, 2012). CF provides individuals with the capacity to utilize opportunities in a complex and rapidly changing world and to cope with such changes (Cropley, 1990; Reiter Palmon, Mumford \& Threlfall, 1998). This process involves processing of more than one piece of information simultaneously, generating a large number of ideas, thinking of alternatives and changing plans to adapt to a certain situation or content (Anderson, 2002; Eslinger \& Grattan, 1993). Cognitive flexibility is defined as the ability to learn from mistakes and feedbacks, to design and select alternative learning strategies, to devise plans and to process information flow concurrently from more than one source (Deak \& Wiseheart 2015; Diamond 2013; Ionescu 2012; Miller \& Cohen 2001). Cognitive flexibility relates to a complex structuring presented not in a solid content but in a more flexible and personal manner (Swindler, 2001). According to Dennis and Vander Wal (2010), CF covers three basic areas; 1) tendency to perceive challenging situations in a controllable way, 2) ability to perceive possible alternatives to the circumstances and human behaviors that take place in life and 3) a skill to generate a number of solutions to resolve challenging situations.

A review of the related literature has revealed that $\mathrm{CF}$ is associated with perceived stress (Altunkol, 2011), expected social competence, authoritative parent attitude and problem-solving ability (Bilgin, 2009), anger, bonding styles, irrational beliefs and psychological symptoms, self-compassion (Martin, Staggers \& Anderson, 2011), openness to changes and post-trauma stress disorder (Palm \& Follette, 2011), and consciousness (Moore \& Malinowski, 2009). CF has also been found associated with being uncontentious and tolerant, verbal aggression (Martin \& Anderson, 1998), a sense of social competence and problem-solving skills (Bilgin, 2009), depression (Merrill, Joiner, Fresco \& Lewinsohn, 2005), cognitive abilities (Carlson \& Moses, 2001; Müller, Zelazo \& Imrisek, 2005), language (Jacques \& Zelazo, 2005), arithmetic skills (Bull \& Scerif, 2001) and coping with stress focusing on problem-solving (Dennis \& Vaner Val, 2010). Studies investigating the relationship between CF and sense of competence have found significant positive correlations between them (Brewster, 2011; Kim \& Omizo, 2005; Shimogori, 2013). As it is seen clearly, there are no studies like the current study exploring the relationships of the CF levels of university students with their perceived quality of faculty life, approaches to learning and academic achievements, which makes this study more significant. In addition, individuals with stronger cognitive flexibility may be better able to choose and make positive approaches to learning active in response to learning situations as compared to children with poorer cognitive flexibility, promoting better academic school readiness (Vitiello, Greenfield, Munis \& George, 2011). 
The investigators have long acknowledged the impact of physical, social, cultural and health-related factors at school level on student outcomes. The term "School Climate" has been accepted as a contextual factor relating to the overall environmental quality within school premises (Anderson, 1982; Zullig, Koopman, Patton \& Ubbes, 2010). School climate generally refers to the physical characteristics of the school building, the social and demographic characteristics of the students and staff, the interpersonal rules and social interactions and the beliefs and values of the individuals at the school (Thapa, Cohen, Guffey \& Higgins-D’Alessandro, 2013). Davis and Peck (1992) describes school climate as a general framework in understanding the nature of schools, feelings perceived by the school environment, relationships between students, teachers, school staff and parents and thoughts relating to whether or not the school is a good environment for learning. While school climate can have a positive impact on learning, it can also be an obstacle for learning. This variable needs to be investigated in the context of cognitive flexibility, learning approaches, and academic achievement.

Academic achievement relates to the activities in the common program as well as perfection in all academic areas at class level (Ganai \& Ashraf, 2013), students' topicbased performances, their ability to obtain information and to express themselves in class and determination of their qualifications related to their assignments at school generally by way of standard tests (Trow, 2004), and "the level of adequacy the student exhibits with respect to the goals of a certain course at the end of that course" (Cevizci, 2010; Shunk, 2009). Kanadli (2016) defines academic achievement as the level reached by students based on their learning experiences in a discipline. Given these explanations, academic achievement can be defined as attaining the goals/gains and qualifications set forth at the beginning of an educational program. Another variable, the effect of which is explored in this study, is the approaches to learning. Approaches to learning have recently become a universal theme in explaining why some students are more successful than others especially in higher education (Bati, Tetik \& Gurpinar, 2010). Approaches to learning are examined in two different categories as surface and deep approaches to learning. SAL is the tendency of those learners who work only to pass their exams with a minimum effort and prefer a structured learning environment. This approach produces low quality learning results in learners. DAL involves comprehending the material being studied and consolidating new information with the previous information (Gordon \& Debus, 2002). Literature review showed that while there are no studies which investigates the relationship of CF with SAL and DAL, on the other hand there are few studies searching the relationship between students' CF levels and their AA. In his study, Lin (2013) found out that cognitive openness to change had a negative impact on academic performance, whereas Yeniad, Malda, Mesman, Van IJzendoorn and Pieper concluded that cognitive flexibility was significantly and equally associated with academic skills.

Besides being individuals who try to adapt to a new environment and system, university students face and try to cope with various challenges including interpersonal relationships and academic competence. Cognitive flexibility and the adopted approaches to learning become important in this process. Compared to those with poor cognitive flexibility, individuals with a greater cognitive flexibility may choose and 
activate positive approaches to learning, which may result in a better academic achievement (Vitiello, Greenfield, Munis \& George, 2011).

The purpose of this study is to explore the relationships between CF levels, perceived quality of faculty life, learning approaches and academic achievements in university students. Additionally, studied here were the extent to which quality of faculty life perceived by the students explains academic achievement based on the mediating variable $\mathrm{CF}$ and the extent to which the students' $\mathrm{CF}$ level explains academic achievement based on the mediating variable approaches to learning.

Cognitive flexibility enables individuals to quickly switch to alternative thoughts in the face of problems and not to be obstructed by them and not to experience a kind of despair. For this reason, even if experiencing negative feelings about faculty life, a person with a high level of cognitive flexibility is assumed not to let such negative feelings to ruin his/her success. Similarly, such individuals are expected to raise their level of achievement regardless of whether they exercise deep or surface learning. This is why cognitive flexibility was taken as a mediating variable in this study. As Baron and Kenny (1986, p. 1176) state, full mediating variable effect shows the ability to zero the relationship between explanatory variable and explained variable.

\section{METHOD}

The study is a correlational comparison type of a study (Fraenkel, Wallen \& Hyun, 2012). Relational survey model researches based on the interaction of variables also contribute to science by providing a perspective to possible prospective research. The selection of the method as descriptive-based relational comparison restricts the interpretation of a causal effect even if there are possible relationships and interactions among variables.

\section{Sample (Participants)}

The study was conducted in 16 faculties of Ankara University. Considering the number of faculties, departments and students it accommodates, Ankara University is one of the largest universities in Turkey. This enabled the researchers to conduct the study with a relatively large sample including students from various faculties. Ankara University has also become one of the 10 research universities in Turkey after it was selected in 2017 as a research university with the decision of the Higher Education Board. The promoting attitude of the University for scientific researches gave the opportunity to collect data easier for this ethics committee approved study.

A permission dated 30/04/2018 and numbered 90 was obtained from the "Ethics SubCommittee for Social Sciences of Ankara University" for the study. The number of registered students in all the faculties of the university was obtained. Using the stratified random sampling method, a sample consisting of 1573 students from all academic units of the university was selected (Sumbuloglu \& Sumbuloglu, 2005). While sampling, the proportion of the number of students studying at the faculties to the total number of undergraduate students was taken into consideration. 
Of the students participating in the study, 1021 (64.9\%) were female and $552(35.1 \%)$ male; $335(21.3 \%)$ were from the Faculty of Languages, History and Geography, 103 (6.5\%) from the Faculty of Science, 122 (7.8\%) from the Faculty of Agriculture, 118 $(7.5 \%)$ from the Faculty of Health Sciences, 144 (9.2\%) from the Faculty of Engineering, 83 (5.3\%) from the Faculty of Educational Sciences, 122 (7.8\%) from the Faculty of Political Sciences, 46 (2.9\%) from the Faculty of Dentistry, 44 (2.8\%) from the Faculty of Pharmacy, $11(0.7 \%)$ from the Faculty of Applied Sciences, $45(2.9 \%)$ from the Faculty of Communication, $163(10.4 \%)$ from the Faculty of Law, $65(4.1 \%)$ from the Faculty of Theology, $4(0.3 \%)$ from the Faculty of Fine Arts, 108 (6.9\%) from the Faculty of Medicine, and 60 (3.8\%) from the Veterinary School. Of the students, 79 $(5 \%)$ were in the preparatory class, $188(12 \%)$ were in their $1^{\text {st }}$ year, $298(18.9 \%)$ in their $2^{\text {nd }}$ year, $349(22.2 \%)$ in their $3^{\text {rd }}$ year, $576(36.6 \%)$ in their $4^{\text {th }}$ year, $66(4.2 \%)$ in their $5^{\text {th }}$ year and $17(1.1 \%)$ in their $6^{\text {th }}$ year.

\section{Data Collection Tools}

Data relating to four variables were collected in this study; students' CF levels, perceived quality of faculty life, approaches to learning and academic achievement. The grade point averages (GPA), as a measurement of students' academic achievement, were obtained from the Student Affairs Information System of Ankara University in the form of a cumulative average of their grades they received from all the courses they took until April 2018 when the data were collected.

The CF levels of the students were found using the Cognitive Flexibility Scale (CFS) developed by Martin and Rubin (1995) and adapted to Turkish for university students by Altunkol (2011). This 6-point Likert-type scale consists of 12 items. The lowest score obtainable from the scale is 12 and the highest 72 . Higher scores indicate higher $\mathrm{CF}$.

The students' perceived quality of faculty life was found using the Quality of Faculty Life Scale (QFLS) developed by Yilmaz and Cokluk Bokeoglu (2006). The scale consists of the "satisfaction from school climate and student relationships (SSCSR)", "satisfaction from faculty members (SFM)" and "satisfaction from faculty (SF)" domains.

The students' approaches to learning was found using the Approaches to Learning Questionnaire (ALQ) developed by Biggs and adapted to Turkish by Bati, Tetik and Gurpinar (2010). The questionnaire consists of the "deep approach to learning (DAL)" and "surface approach to learning (SAL)" subscales.

\section{Data Analysis}

In line with the questions of the study, the data analysis should involve correlation analyses and path analyses. In order for the variance and covariance matrices to be of positive definition in the path analysis, the data must show a multivariate normal distribution (Ozdemir, 2013). The variables are again expected to show a multivariate normal distribution in structural equation modeling (SEM) and path analysis (Kline, 2011). The data obtained from the CFS, QFLS, ALQ and the GPAs were made subject 
to "Kolmogorov-Smirnov Normal Distribution Test" (Kalayci, 2005; Ozdamar, 2013) and "Doornik-Hansen Multivariate Normal Distribution Test". As a result of the normal distribution tests applied, all data except CFS scores and GPAs were found normally distributed. The correlations in normally distributed scores were calculated with "Pearson Moments Multiplication Correlation Coefficient" and in other scores with "Spearman Brown Rank Correlation Coefficient". The Pearson correlation analysis is meant to be a parametric relationship analysis and requires a normal distribution. The Spearman Brown rank correlation coefficient, on the other hand, is a nonparametric correlation analysis. The normal distribution studied with a single variable was also studied under a multivariate normal distribution assumption using the STATA 14 program. Any of the available tests for multivariate normal distribution can be applied to the data. One such test is Doornik-Hansen test and it can be run on the STATA package program. The test results are summarized in Table 1.

Table 1

Doornik-Hansen Multivariate Normal Distribution Test Results

\begin{tabular}{llll}
\hline Variables & $X^{2}$ & df & p \\
\hline SF*SFM*SSCSR*DAL*SAL*CFS*GPA & 8.12 & 14 & 0.102 \\
\hline
\end{tabular}

It is understood from Table 1 that a total of 5 subscales of the two different scales, CFS and GPAs show a multivariate normal distribution ( $\mathrm{p}>.05)$. Upon this result, a path analysis model was decided to be set up.

\section{FINDINGS}

\section{Correlations between Variables}

The correlations between the students' PQFL, AL, CF levels and AA were explored. The results obtained are summarized in Table 2.

Table 2

Correlations between Variables

\begin{tabular}{|c|c|c|c|c|c|c|}
\hline & $\sqrt{\Omega}$ & $\sum_{\substack{S \\
s}}$ & $\begin{array}{l}\tilde{U} \\
\tilde{N} \simeq\end{array}$ & 离 & 空 & U \\
\hline SF & 1 & & & & & \\
\hline SFM & $0.840^{* *}$ & 1 & & & & \\
\hline SSCSR & $0.786^{* *}$ & $0.657 * *$ & 1 & & & \\
\hline DAL & $0.951 * *$ & $0.800 * *$ & $0.732 * *$ & 1 & & \\
\hline SAL & $-0.746^{* *}$ & $-0.650 * *$ & $-0.708 * *$ & $-0.789 * *$ & 1 & \\
\hline $\mathrm{CF}$ & $0.924 * *$ & $0.784 * *$ & $0.723 * *$ & $0.981 * *$ & $-0.784 * *$ & 1 \\
\hline AA & $0.705^{* *}$ & $0.573 * *$ & $0.502 * *$ & $0.631^{* *}$ & $-0.421 * *$ & $0.602 * *$ \\
\hline
\end{tabular}

$* \mathrm{p}<.05, * * \mathrm{p}<.01, * * * \mathrm{p}<.001$

Table 2 shows that SF had a high level of significant positive correlation with SFM, SSCSR, DAL, CF and AA ( $p<.05)$. There was a high level (Buyukozturk, 2013) of significant negative correlation between SF and SAL ( $\mathrm{p}<.05)$. A high level of significant positive correlation was also found between SFM and deep approach to learning, CF $(\mathrm{p}<.05)$. SFM was found to have a moderate level of significant positive correlation with 
SSCSR and AA ( $\mathrm{p}<.05)$. There was a moderate level of significant negative correlation between SFM and SAL $(\mathrm{p}<.05)$. A high level of significant positive correlation was found between SSCSR relationships and deep approach to learning, CF $(p<.05)$. A moderate level of significant positive correlation was found between SSCSR and AA $(\mathrm{p}<.05)$. There was a high level of significant negative correlation between SSCSR and SAL $(\mathrm{p}<.05)$. There was a high level of significant negative correlation between DAL and SAL $(\mathrm{p}<.05)$. A high level of significant positive correlation was found between DAL and CF $(\mathrm{p}<.05)$. There was a moderate level of significant positive correlation between DAL and AA ( $p<.05)$. There was a high level of significant negative correlation between SAL and CF ( $\mathrm{p}<.05)$. There was a moderate level of significant negative correlation between SAL and AA $(\mathrm{p}<.05)$. A moderate level of significant positive correlation was found between $\mathrm{CF}$ and AA $(\mathrm{p}<.05)$.

\section{The Effect of Perceived Quality of Faculty Life on Academic Achievement Based} on the Mediating Variable CF

When the students' CF levels were taken as the mediating variable, the effect of their perceived quality of faculty life on AA was explored. The diagram of the path analysis performed is shown in Figure 1.

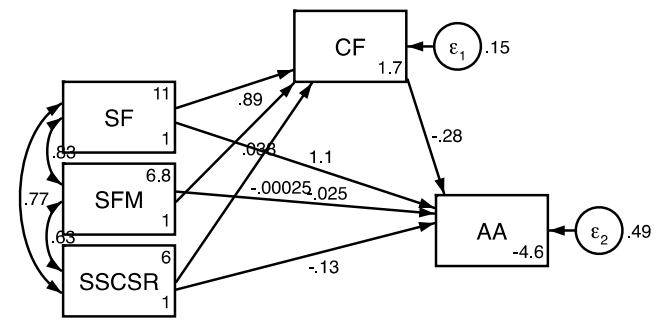

Figure 1

Based on the mediating variable of CF, the effect of PQFL on AA (standardized estimations) (SF: Satisfaction from Faculty; SFM: Satisfaction from Faculty Members; SSCSR: Satisfaction from School Climate and Student Relationships; CF: Cognitive Flexibility; AA: Academic Achievement)

For the path analysis in Figure 1, "chi-square $\left(X^{2}\right)$ was found to be 0, degree of freedom 0 , "Goodness of Fit Index (GFI) 1, "Root Mean Square Error of Approximation (RMSEA)" 0.696 and "Root Mean Square Residual (RMR)" 0. This goodness of fit indexes was not within the acceptable range as shown in the literature (Joreskog and Sorbom, 1993; Kline, 2011; Sumer, 2000; Ozdamar, 2013). The model's goodness of fit indexes not being within the acceptable range led to the rejection of the model based on the mediating variable of CF. However, some of the regression estimations in the model were significant. These estimations are summarized in Table 3. 
Table 3

Regression Estimations

\begin{tabular}{llcccc}
\hline & & Coefficient & Standard Error & $\mathrm{Z}$ & $\mathrm{p}$ \\
\hline \multirow{5}{*}{ Direct Effect } & 1.26 & .03 & 40.95 & .000 \\
& SF $\rightarrow$ CF & .04 & .02 & 2.12 & .034 \\
& SFM $\rightarrow$ CF & -.01 & .03 & -.02 & .987 \\
& SSCSR $\rightarrow$ CF & -.06 & .01 & -6.26 & .000 \\
& CF $\rightarrow$ AA & .32 & .02 & 19.33 & .000 \\
& SF $\rightarrow$ AA & -.01 & .01 & -.79 & .430 \\
& SFM $\rightarrow$ AA & -.06 & .01 & -4.67 & .000 \\
\hline \multirow{5}{*}{ Indirect Effect } & SSCSR $\rightarrow$ AA & -.08 & .01 & -6.19 & .000 \\
& SF $\rightarrow$ CF $\rightarrow$ AA & -.01 & .01 & -2.01 & .045 \\
& SFM $\rightarrow$ CF $\rightarrow$ AA & .00 & .00 & .02 & .987 \\
\hline
\end{tabular}

A review of Table 3 showed that SF was a significant positive explanatory variable for CF ( $p<.05)$. SF was also a significant positive explanatory variable for AA $(p<.05)$. SSCSR was a significant negative explanatory variable for AA $(p<.05)$. CF was a significant negative explanatory variable for AA $(\mathrm{p}<.05)$. Looking at the indirect effects, the variable SF, which was a positive explanatory variable for AA, has become a negative explanatory variable for AA with respect to the mediating variable $\mathrm{CF}$. In other words, SF has become a variable reducing AA. The variance explained in the model was $49 \%$ for AA and $15 \%$ for CF.

\section{The Effect of Approaches to Learning on Academic Achievement Based on the Mediating Variable CF}

When the students' CF levels were taken as the mediating variable, the effect of their approaches to learning on AA was explored. The diagram of the path analysis performed is shown in Figure 2.

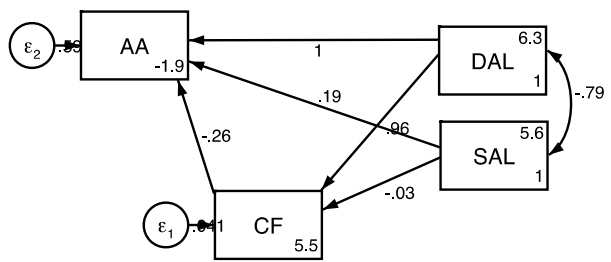

Figure 2

Based on the mediating variable of $\mathrm{CF}$, the effect of $\mathrm{AL}$ on $\mathrm{AA}$ (standardized estimations) (DAL: Deep Approach to Learning; SAL: Surface Approach to Learning; CF: Cognitive Flexibility; AA: Academic Achievement)

For the path analysis in Figure 2, "chi-square $\left(X^{2}\right)$ was found to be 0, degree of freedom 0, GFI 1, RMSEA 0.298 and RMR 0. This goodness of fit indexes was not within the acceptable range as shown in the literature (Joreskog and Sorbom, 1993; Kline, 2011; 
Sumer, 2000; Ozdamar, 2013). The regression estimations in the model are summarized in Table 4.

Table 4

Regression Estimations

\begin{tabular}{llcccc}
\hline & & Coefficient & Standard Error & $\mathrm{Z}$ & $\mathrm{p}$ \\
\hline Direct Effect & $\mathrm{DAL} \rightarrow \mathrm{CF}$ & .86 & .01 & 114.89 & .000 \\
& $\mathrm{SAL} \rightarrow \mathrm{CF}$ & -.03 & .1 & -3.66 & .000 \\
& $\mathrm{CF} \rightarrow \mathrm{AA}$ & -.05 & .02 & -2.71 & .007 \\
& $\mathrm{DAL} \rightarrow \mathrm{AA}$ & .19 & .02 & 10.66 & .000 \\
& $\mathrm{SAL} \rightarrow \mathrm{AA}$ & .04 & .01 & 5.98 & .000 \\
\hline Indirect Effect & $\mathrm{DAL} \rightarrow \mathrm{CF} \rightarrow \mathrm{AA}$ & -.05 & .02 & -2.71 & .007 \\
& $\mathrm{SAL} \rightarrow \mathrm{CF} \rightarrow \mathrm{AA}$ & .01 & .00 & 2.18 & .029 \\
\hline
\end{tabular}

A review of Table 4 showed that DAL was a significant positive explanatory variable for $\mathrm{CF}(\mathrm{p}<.05)$. SAL was a significant negative explanatory variable for $\mathrm{CF}(\mathrm{p}<.05)$. $C F$ was a significant negative explanatory variable for AA $(\mathrm{p}<.05)$. SAL was a significant positive explanatory variable for AA $(\mathrm{p}<.05)$. DAL was a significant positive explanatory variable for AA $(\mathrm{p}<.05)$. The variance explained in the model was $58 \%$ for $\mathrm{AA}$ and $4 \%$ for $\mathrm{CF}$.

When the analyses are evaluated all together, CF is found significantly correlated with AA. A low level of CF can reverse the normally positive (improving) effects of the significant explanatory variables' SF and DAL on AA. However, it is essential to make this comment under the limitation that the path models have not been confirmed by the goodness of fit indices.

\section{DISCUSSION AND CONCLUSION}

As a result of the study, the three subscales of the QFLS were found to have a significant positive correlation with DAL, CF and AA, and a significant negative correlation with SAL.

From the learning approaches, the DAL was found to have a significant positive correlation with CF, AA and the subscales of the QFLS, and SAL showed a negative correlation. While SAL was a negative explanatory variable for $\mathrm{CF}$, it was a positive explanatory variable for AA. DAL was a positive explanatory variable for AA. According to the estimations in the path analysis models, it can be said that $\mathrm{CF}$, which involves DAL as well as the ability to freely switch from one thought to another when generating more than one strategy to various problems (Stevens, 2009), contributes to the academic achievement of students. There are some evidences in the literature showing that CF is associated with preparedness to study (Vitiello et al., 2011) and academic achievement (Yeniad et al., 2013). It was found in the study of Alper and Deryakulu (2008) that the variable CF did not produce any significant difference in students' achievement, attitudes or permanence of learning. In the study of Yucel (2011), however, a positive linear correlation was found between student achievement and CF. There was a significant correlation between $\mathrm{CF}$ scores and success in 
examinations, and the students with a high level of CF were found to be more successful. Yucel, Karahoca and Karahoca (2015) also found in their study a positive linear correlation between $\mathrm{CF}$ and student achievement. It can be commented that students with higher level of $\mathrm{CF}$ are more successful. Kercood, Lineweaver, Frank and Fromm (2017) have found in their study that CF is an important predictor of AA according to the results of the Woodcock Johnson Tests of Achievement. The results of their study have demonstrated that reading skills, mathematical skills and writing skills are all associated with CF; in other words, CF has major effects on AA.

CF level had a significant positive correlation with all the variables other than SAL. AA had also a significant positive correlation with all the variables other than SAL. The studies conducted on approaches to learning are important for academicians and teachers in helping learners understand how they can use various approaches in problem-solving. Use of appropriate approaches in learning has made it easier for students to find solutions more readily in problem-solving during learning and increased their academic achievements (Spicer, 2004).

Although CF showed a positive correlation with AA in Table 2, it has a negative explanatory role for AA when it was included in the model as a mediating variable. Although previous studies have not focused on academic achievement alone, studies made with university students have shown that increased CF is associated with lower anxiety, higher motivation and success in educational programs (Timarova \& Salaets, 2011). These results show that CF influences learning, linguistic improvement (Deák, 2004; Jacques \& Zelazo, 2005) and mathematical skills (Bull \& Scerif, 2001); shortly speaking, there may be a connection between $\mathrm{CF}$ and achievement in academic environments. Although there are not very many studies supporting the relationship between CF and success, Vitello et al. (2011) argued that CF was associated with attention and regular monitoring of targets. Vitello et al. (2011) also found that CF depended on learning-related attitudes such as frustration tolerance in academic environments and the type of interactions between individuals in relation to learning. Given these, it is possible to say that $\mathrm{CF}$ is actually associated with academic experiences and the deficiencies in CF lead to decreased academic performance. The study made by Spiro and Jehng (1990) has shown that cognitive skills including CF are very important in improving effective problem-solving skills as common knowledge is always linked to the new concepts in the academic environment. However, studies have demonstrated that it is not fully recognizable in advance whether CF is directly associated with academic performance (Wixted, Sue, Dube \& Potter, 2016).

The regression estimations in the path analysis model revealed that SF was a positive explanatory variable for AA and SSCSR was a negative explanatory variable for AA. Conversely, a special importance is attributed to the quality of school life by the administrators and teachers because they find the quality of school life associated with the academic achievements of students. Despite the fact that students' reactions to teachers and their loyalty to school is important also for the effectiveness of the school (Epstein \& McPartland, 1976), increased SSCSR led to decreased academic achievement and decreased SSCSR had an enhancing effect on academic achievement in 
the current study. Finally, Martin and Rubin (1995) have argued that individuals who state that they are cognitively flexible see themselves more competent than those who are not cognitively flexible. From this point of view, it can be said that there is a mutual indicator type of relationship between CF and sense of competence, which is defined as the ability to organize the actions necessary for successful completion of a performance and the perceived capacity to materialize such actions (Bandura, 1986). When defining the concept of CF, Martin, Anderson and Thweatt (1998) also mentioned that sense of competence is a major component of $\mathrm{CF}$. Therefore, owing to $\mathrm{CF}$, individuals will be able to overcome any academic, social or emotional adversity they may have to face.

It should be noted that the present study is limited to undergraduates of Ankara University. This may raise a problem in generalizing the results. Further studies to be carried out with larger groups and in different universities will underline the significance of the variables used in this study. However, as stated by Celikkaleli (2014), it should be borne in mind that the variable cognitive flexibility can both have a direct causal effect and serve as a mediating variable due to the nature of this type of studies.

In conclusion, this study aimed to demonstrate the cognitive flexibility levels, perceived quality of faculty life, learning approaches, and academic achievements in university students and exploring the relationships between these variables. As a result of the study, the three subscales of the quality of faculty life scale (satisfaction from faculty, satisfaction from faculty members and satisfaction from school climate and student relationships) were found positively correlated with deep approach to learning, cognitive flexibility and academic achievement, and negatively correlated with surface approach to learning. Based on the findings of the study, students should be encouraged to use deep learning approaches which requires using cognitive flexibility to perform a range of activities, which may lead to academic achievement. In addition, a longitudinal study measuring $\mathrm{CF}$, PQFL, LA, and AA over time is needed to explore these relations. Because future studies should attempt to better understand influences on students' cognitive flexibility by including quality of faculty life, learning approaches, and academic achievement. Considering cognitive flexibility as a skill that can be improved, the results of this study suggest that psycho-training programs need to be developed and implemented for individuals with a lower cognitive flexibility level. Such psychotraining programs can also be used at earlier periods to promote deep learning approaches, improved academic skills and the awareness that the school is a good learning environment, which would further improve emotional and social skills.

\section{REFERENCES}

Alper, A., \& Deryakulu, D. (2008). The effect of cognitive flexibility on students' achievement and attitudes in Web mediated problem-based learning. Education and Science, 33(148), 49-63.

Altunkol, F. (2011). The analysis of the relation between cognitive flexibility and perceived stress levels of college students (Unpublished master thesis). Cukurova University, Adana. 
Anderson, P. (2002). Assessment and development of executive function (EF) during childhood. Child Neuropsychology, 8(2), 71-82. doi: 10.1076/chin.8.2.71.8724.

Anderson, C. S. (1982). The search for school climate: A review of the research. Review of Educational Research, 52, 368-420. doi: 10.3102/00346543052003368.

Bandura A. (1986). Social foundations of thought and action: A social cognitive theory. Englewood Cliffs, NJ: Prentice- Hall.

Baron, R. M., \& Kenny, D. A. (1986). The moderator mediator variable distinction in social psychological research: Conceptual, strategic, and statistical considerations. Journal of Personality and Social Psychology, 51(6), 1173-1182. doi: 10.1037/00223514.51.6.1173.

Bati, A. H., Tetik, C., \& Gurpinar, E. (2010). Assessment of the validity and reliability of the Turkish adaptation of the study process questionnaire (R-SPQ-2F). Türkiye Klinikleri J. Med. Sci., 30(5), 1639-1646. doi: 10.5336/medsci.2009-15368.

Bilgin. M. (2009). Some variables predicting cognitive flexibility. Cukurova University Faculty of Education Journal, 36(3), 142-157.

Brewster, M. E. (2011). The roles of cognitive flexibility, bicultural self-efficacy, and minority stress in the mental health of bisexual individuals (Unpublished doctoral dissertation). University of Florida, USA.

Bull, R., \& Scerif, G. (2001). Executive functioning as a predictor of children's mathematics ability: Inhibition, switching, and working memory. Developmental Neuropsychology 19, 273-293. doi: 10.1207/S15326942DN1903_3.

Buyukozturk, S. (2013). Sosyal bilimler için veri analizi el kitabı [Manual of data analysis for social sciences]. Ankara: Pegem.

Carlson, S. M., \& Moses, L. J. (2001). Individual differences in inhibitory control and children's theory of mind. Child Development, 72, 1032-1053. doi: 10.1111/14678624.00333 .

Cevizci, A. (2010). Eğitim sözlüğü [Glossary of education]. İstanbul: Say.

Cropley, A. J. (1990). Creativity and mental health in everyday life. Creativity Research Journal, 3(3), 167-178. doi:10.1080/10400419009534351.

Celikkaleli, O. (2014). The validity and reliability of the cognitive flexibility scale. Education and Science, 39(176), 339-346. doi: 10.15390/EB.2014.3466.

Davis, L. E., \& Peck, H. I. (1992). Outcome measures school climate: Curriculum and instruction. Paper presented at the Annual Meeting of the Mid-South Educational Research Association, Knoxville, TN.

Déak, G. O. (2004). The development of cognitive flexibility and language abilities. Advances in Child Development and Behavior, 31, 271-327. doi: 10.1016/S00652407(03)31007-9. 
Déak, G. O., \& Wiseheart, M. (2015). Cognitive flexibility in young children: General or task-specific capacity? Journal of Experimental Child Psychology, 138, 31-53. doi: 10.1016/j.jecp.2015.04.003.

Dennis J. P., \& Vander Wal, J. S. (2010). The cognitive flexibility inventory: Instrument development and estimates of reliability and validity. Cognitive Therapy and Research, 34, 241-253. doi: 10.1007/s10608-009-9276-4.

Diamond, A. (2013). Executive functions. The Annual Review of Psychology, 64, 135168. doi: 10.1146/annurev-psych-113011-143750.

Epstein, J. L., \& McPartland, J. M. (1976). The concept and measurement of the quality of school life. American Educational Research Journal, 13(1), 15-30. doi: 10.3102/00028312013001015.

Eslinger, P. J., \& Grattan, L. M. (1993). Frontal lobe and frontal-striatal substrates for different forms of human cognitive flexibility. Neuropsychologia, 31(1), 17-28. doi: 10.1016/0028-3932(93)90077-D.

Fraenkel, J. R., Wallen, N. E., \& Hyun, H. H. (2012). How to design and evaluate research in education. USA: McGraw-Hill Companies Inc.

Ganai, M. Y., \& Ashraf, M. (2013). A Comparative study of adjustment and academic achievement of college students. Journal of Educational Research and Essays, 1(1),5-8.

Gordon, C., \& Debus, R. (2002). Developing deep learning approaches and personal teaching efficacy within a preservice teacher education context. $\mathrm{Br} J$ Educ Psychol, 72(4), 483-511. doi: 10.1348/00070990260377488.

Gulum, I. V., \& Dag, I. (2012). The Turkish adaptation, validity and reliability study of the repetitive thinking questionnaire and the cognitive flexibility inventory. Anatolian Journal of Psychiatry, 13, 216-223.

Ionescu, T. (2012). Exploring the nature of cognitive flexibility. New Ideas in Psychology, 30(2), 190-200. doi: 10.1016/j.newideapsych.2011.11.001.

Jacques, S., \& Zelazo, P. D. (2005). Language and the development of cognitive flexibility: Implications for theory of mind. In J. W. Astington, \& J. A. Baird (Eds.), Why language matters for theory of mind (pp. 144-162). Oxford: Oxford University Pres.

Joreskog, K. G., \& Sorbom, D. (1993). Lisrel 8: Structural equation modeling with the simplis command language. Hillsdale: Erlbaum Associates Publishers.

Kalayci, S. (2005). SPSS uygulamalı çok değişkenli istatistik teknikleri [SPSS applied multivariate statistical techniques]. Ankara: Asil.

Kanadli, S. (2016). A meta-analysis on the effect of instructional designs based on the learning styles models on academic achievement, attitude and retention. Educational Sciences: Theory \& Practice, 16(6), 2057-2086. doi: 10.12738/estp.2016.6.0084. 
Kercood, S., Lineweaver, T. T., Frank, C. C., \& Fromm, E. D. (2017). Cognitive flexibility and its relationship to academic achievement and career choice of college students with and without attention deficit hyperactivity disorder. Journal of Postsecondary Education and Disability, 30(4), 329-44.

Kim, B. S. K., \& Omizo, M. M. (2005). Asian and European American cultural values, collective self-esteem, acculturative stress, cognitive flexibility, and general self-efficacy among Asian American college students. Journal of Counseling Psychology, 52(3), 412419. doi: 10.1037/0022-0167.52.3.412.

Kline, R. B. (2011). Principles and practice of structural equation modeling. USA: The Guilford Press.

Lin, Y. W. (2013). The effects of cognitive flexibility and openness to change on college students' academic performance. Doctorate Dissertation. La Sierra University.

Martin, M. M., \& Rubin, R. B. (1995). A new measure of cognitive flexibility. Psychological Reports, 76, 623-626. doi: 10.2466/pr0.1995.76.2.623.

Martin, M. M., Anderson, C. M., \& Thweatt, K. S. (1998). Aggressive communication traits and their relationship with the cognitive flexibility scale and the communication flexibility scale. Journal of Social Behavior and Personality, 13(3), 34-45.

Martin, M. M., Staggers, S. M., \& Anderson, C. M. (2011). The relationships between cognitive flexibility with dogmatism, intellectual flexibility, preference for consistency, and self-compassion. Communication Research Reports, 28(3), 275-280, doi: 10.1080/08824096.2011.587555.

Martin, M. M., \& Anderson, C. M. (1998). The cognitive flexibility scale: Three validity studies. Communication Repots, 11, 1-9. doi: 10.1080/08934219809367680.

Merrill, K., Joiner, T., Fresco, D. M., \& Lewinsohn, P. (2005). Relationship of cognitive flexibility to depression and anxiety symptoms in a large community sample of high school students. A poster presented at the annual meeting of the Association of Behavioral and Cognitive Therapies, Washington, DC.

Miller, E. K., \& Cohen, J. D. (2001). An integrative theory of prefrontal cortex function. Annual Review of Neuroscience, 24(1), 167-202. doi: 10.1146/annurev.neuro.24.1.167.

Moore, A., \& Malinowski, P. (2009). Meditation, mindfulness and cognitive flexibility. Consciousness and Cognition, 18, 176-186. doi: 10.1016/j.concog.2008.12.008.

Muller, U., Zelazo, P. D., \& Imrisek, S. (2005). Executive function and children's understanding of false belief: How specific is the relation? Cognitive Development, 20, 173-189. doi: 10.1016/j.cogdev.2004.12.004.

Ozdamar, K. (2013). Paket programlar ile istatistiksel veri analizi [Statistical data analysis with package programs]. Eskishehir: Nisan.

Palm, K. M., \& Follette, V. M. (2011). The roles of cognitive flexibility and experiential avoidance in explaining psychological distress in survivors of interpersonal 
victimization. Journal of Psychopathology and Behavioral Assessment, 33, 79-86. doi: 10.1007/s10862-010 9201-x.

Reiter Palmon, R., Mumford, M. D., \& Threlfall, K. V. (1998). Solving everyday problems creatively: The role of problem construction and personality type. Creativity Research Journal, 11(3), 187-197. doi:10.1207/s15326934crj1103_1.

Spicer, D. P. (2004). The impact of approaches to learning and cognition on academic performance in business and management. Emerald Education Training, 46(4), 194205. doi: 10.1108/00400910410543982.

Spiro, R. J., \& Jehng, J. C. (1990). Cognitive flexibility and hypertext: Theory and technology for the nonlinear and multidimensional traversal of complex subject matter. In D. Nix, \& R. Spiro (Eds.), Cognition, education and multimedia: Exploring ideas in high technology. Hillsdale, NJ: Lawrence Erlbaum.

Shimogori, Y. (2013). Impact of biculturalism on self-efficacy and cognitive flexibility of Japanese adults (Unpublished doctoral dissertation). Claremont Graduate University and San Diego State University, USA.

Shunk, D. H. (2009). Öğrenme teorileri. (Çev. Ed. M. Şahin). İstanbul: Say.

Stevens, A. D. (2009). Social problem-solving and cognitive flexibility: Relations to social skills and problem behavior of at-risk young children (Unpublished doctoral dissertation). Seattle Pacific University. USA.

Sumbuloglu, V., \& Sumbuloglu, K. (2005). Klinik ve saha araştırmalarında örnekleme yöntemi ve örneklem büyüklüğ̈̈ [Sampling method and sample size in clinical and field researches]. Ankara: Alp Ofset.

Sumer, N. (2000). Structural equation models: Basic concepts and sample applications. Türk Psikoloji Yazıları, 3(6), 49-73.

Swindler, G. (2001). Spiro's cognitive flexibility theory: Examining the theory through a literature review. Fort Hays State University.

Thapa, A., Cohen, J., Guffey, S., \& Higgins D’Alessandro, A. (2013). A review of school climate research. Review of Educational Research, 83, 357-385. doi: 10.3102/0034654313483907.

Timarova, S., \& Salaets, H. (2011). Learning styles, motivation and cognitive flexibility in interpreter training: Self-selection and aptitude. Interpreting, 13, 31-52. doi: 10.1075/intp.13.1.03tim.

Trow. (2004) Academic achievement. In Dandapani (Eds.), A text book of advanced educational psychology (pp. 434-439). New Delhi: Atlantic Publishers.

Vitiello, V. E., Greenfield, D. B., Munis, P., \& George, J. (2011). Cognitive flexibility, approaches to learning, and academic school readiness in head start preschool children. Early Education \& Development, 22(3), 388-410. doi: 10.1080/10409289.2011.538366. 
Wixted, E. K., Sue, I. J., Dube, S. L., \& Potter, A. S. (2016). Cognitive flexibility and academic performance in college students with ADHD: An fMRI study. UVM Honors College Senior Theses.

Yeniad, N., Malda, M., Mesman, J., Van IJzendoorn, M. H., \& Pieper, S. (2013). Shifting ability predicts mathand reading performance in children: A meta-analytical study. Learning and Individual Differences, 23, 1-9. doi: 10.1016/j.lindif.2012.10.004.

Yilmaz, K., \& Cokluk Bokeoglu, O. (2006). The quality of faculty life scale a study on validity and reliability. The Journal of Turkish Educational Sciences, 4(2), 201-210.

Yucel, O. (2011). The effects of problem based learning on cognitive flexibility, selfregulation skills and students' achievements (Unpublished master thesis). Bahceshehir University, Istanbul.

Yucel, O., Karahoca, D., \& Karahoca, A. (2015). The effects of problem-based learning on cognitive flexibility, self-regulation skills and students' achievements. Global Journal of Information Technology, 6(1), 86-93.

Zullig, K. J., Koopman, T. M., Patton, J. M., \& Ubbes, V. A. (2010). School climate: Historical review, instrument development, and school assessment. Journal of Psychoeducational Assessment, 28, 139-152. doi: 10.1177/0734282909344205. 